\title{
O DESPERTAR PARA A LEITURA
}

\author{
Marlene Pissolito Campos*
}

Resumo: Neste relato, apresento as atividades realizadas em sala de aula, a partir das quais foi possível motivar alunos, para que se envolvessem com o processo de leitura.

Palavras-chave: língua portuguesa, leitura, ensino, PCN.

\section{Introdução}

Não é incomum a observação de alguns professores de língua portuguesa quanto ao fato de que muitos de seus alunos apresentam dificuldades no desenvolvimento de atividades durante as aulas de leitura.

Minha experiência indica que há necessidade de motivação por parte do professor em relação ao aluno e que é importante observar a Metodologia a ser aplicada, para que se altere esse quadro.

\section{A importância inquestionável do hábito da leitura}

Dizer da importância da leitura em qualquer fase da vida humana é ser demasiado repetitiva em relação aos estudiosos e professores que nos precederam.

De acordo com Dumond (2002:1)

$\mathrm{O}$ ato da leitura não se efetiva em ações isoladas, nem mesmo lineares, mas sim em decorrência de complexa reação em cadeia de ações, sentimentos, desejos, especulações na bagagem de conhecimentos armazenados, motivações, análises,

Graduada em Letras, com especialização em Língua Portuguesa. Professora do Colégio Bandeirantes/São Paulo-SP. 
críticas do leitor. A leitura é uma experiência e encontra-se submetida a diversas variáveis que não podem deixar de ser verificadas, ao se tentar teorizá-la."

A prática leva-nos a aceitar completamente a posição da estudiosa Lígia Dumond. São muitos os elementos que merecem ser considerados, se quisermos alcançar resultados significativos quanto ao desempenho dos alunos nas aulas de leitura.

\section{O papel do Professor}

Frente às dificuldades que os alunos apresentam, o professor precisa encontrar alternativas que viabilizem sua aula e que permitam ao aluno desenvolver suas habilidades de leitura em língua materna.

O papel que deve desempenhar o professor passa por seu conhecimento teórico sobre o processo de leitura e passa por seu conhecimento pedagógico sobre as práticas necessárias para alcançar objetivos a que se propõe.

\section{A orientação dos PCN}

Desde 1998, os PCN apresentam posições que se pretendem adequadas quanto ao ensino de língua materna. Dedicam páginas específicas direcionadas aos níveis de escolaridade, com o intuito de aparelhar professores a conhecerem os objetivos teóricos da proposta e a conseguirem um rendimento adequado dos alunos no processo de leitura.

Observemos o que dizem Lombardi e Arbolea (s.d.:p.4) sobre os Parâmetros:

Os PCN definem o leitor competente como alguém capaz de compreender integralmente aquilo que lê, ultrapassando o nível explícito a ponto de identificar elementos implícitos. Além disso, estabelecer relações entre os textos que lê e outros já conhecidos, atribuindolhes sentidos e ainda justificar e validar a sua leitura a partir da localização de elementos discursivos. Alguém que possui aptidão para selecionar trechos que atendam a uma necessidade sua e utiliza estratégias de leitura de forma a atingir essa exigência.

O que entendemos é que a preocupação dos Parâmetros Curriculares Nacionais está mais em definir o que é um leitor competente do que em observar a realidade de sala de aula, em que muitos alunos não se sentem, por várias razões, motivados a iniciarem, se entregarem, se permitirem uma leitura. Como o aluno estabelecerá relações entre textos, se nem quer aceitar o processo de leitura, nem pegar em um livro? 


\section{Uma experiência em sala de aula}

Em uma sala de $6^{a}$ série do ensino fundamental, deparei-me com uma aluna $(\mathrm{N})$, muito esperta, mas desmotivadíssima quanto à participação nas aulas de leitura em língua portuguesa. Tal aluna era muito determinada: só fazia o que tinha vontade. No dia de trazer para a aula o livro paradidático Mau começo de Lemony Snicket (Companhia das Letrinhas), indicado para o bimestre, para o aquecimento que faço com os alunos, ela não o trouxe, pois afirmou que não gostava de ler e disse em bom tom que nunca lera nenhum livro até o fim, alegando que sentia-se desmotivada a continuar a leitura, achando os livros "sem graça".

Eu me senti diante da grande tarefa - conseguir alterar tal comportamento, a partir de uma interação adequada. $\mathrm{Na}$ verdade, eu esperava que ela mudasse de opinião durante o ano letivo.

\subsection{Os passos}

Dei continuidade às aulas utilizando-me dos passos que eu já havia testado e selecionado como bom andamento às aulas de leitura. Assim descrito: Aquecimento; levantamento do vocabulário a ser pesquisado; pesquisa no dicionário; verificação da leitura do livro; chamada oral do vocabulário pesquisado e corrigido; atividades no laboratório multidisciplinar.

Aquecimento - sabendo-se que os alunos já conheciam o livro num primeiro contato com a leitura, foi possível criar um envolvimento, a partir da leitura de segmentos do livro. Procedeu-se a paradas para levantamento de hipóteses que eles faziam sobre palavras desconhecidas; buscavam-se sinônimos daqueles termos que eles não conseguiam saber o que significavam, ressaltando momentos importantes da história, esmiuçando passagens mais difíceis, lendo de maneira dramatizada alguns trechos, para que eles seguissem tudo, acompanhando com muito interesse e atenção.

A atividade é sempre interrompida num momento de grande curiosidade, para que o aluno se interesse em saber o que vai acontecer na sequência da narrativa

A continuação da leitura é feita em casa no ritmo do aluno. (A maioria deles comenta que não vê a hora de chegar em casa para continuar a ler e leem mesmo.

No dia seguinte a essa atividade, perguntei a N. se já havia começado a ler o livro e ela me disse que não. Não perguntei mais e nem falei sobre a importância de se ler etc.

Levantamento do vocabulário a ser pesquisado - nesse trabalho com a leitura, eu e outra colega professora, minha parceira de série, passamos um grande número de palavras do livro, que constituem dificuldades para $5^{\mathrm{a}}$ série, a fim de que os alunos procurem os sinônimos em casa, um pouco por dia. Durante as aulas, os alunos comentam que já pesquisaram tantas palavras, ou que não acharam o significado de tal termo, ou não entenderam o que o dicionário trouxe e assim por diante. A aluna $\mathrm{N}$ acompanhava tudo isso sem falar nada comigo sobre o livro. 
Conferência da pesquisa ao dicionário - após passar essas palavras na tela (num dia agendado) e explorar o sentido de cada uma, para confirmar se os alunos souberam escolher o melhor significado para o contexto, é realizada uma chamada oral sobre o vocabulário do livro. Para essa atividade, eles se preparam muito, estudam muito e há um tipo de competição entre eles (que não é estimulada - parece que é próprio de aluno pequeno) e todos querem acertar as cinco palavras que cabem para cada um.

A aluna $\mathrm{N}$ fez o vocabulário no caderno, como todos os colegas. Como não devia ter lido o livro, durante a aula da "correção" do vocabulário, ela ficou ocupada o tempo todo só apagando e corrigindo, pois não contextualizara os sinônimos.

Avaliação da leitura do livro - os alunos (em grupo ou individualmente) respondem a questões de compreensão e interpretação da narrativa lida.

Faltando dois dias para a prova sobre o livro, a aluna $\mathrm{N}$ veio até minha mesa, no final da aula, e disse com um ar de muita satisfação que lera o livro até o fim e gostara muito.

Depois de poucas aulas, ela trouxe o outro livro na aula de aquecimento, teve uma participação muito ativa na tentativa de descobrir os sinônimos das palavras e passou a mostrar prazer em ler. Após um mês, disse-me que estava gostando muito de ler e não sabia que livro era bom. Disse ainda que fora a uma livraria com a mãe onde juntas escolheram alguns títulos e que ela iria ler todos.

$\mathrm{Na}$ volta às aulas, em agosto, ela falou sobre as leituras de férias, deu o nome dos livros que lera e confirmou o quanto havia gostado da descoberta da leitura. Nesse dia, num certo momento, parei a aula e perguntei se ela queria dizer para a classe a experiência que tivera com livros, considerando aquela impressão negativa que apresentara no início do ano. Ela aceitou e falou alto para que todos os colegas ouvissem. Ela contou para a classe sobre os progressos que fizera e que estava adorando ler. Todos perceberam nela a mudança de comportamento em relação à leitura.

A aluna $\mathrm{N}$ e eu vimos surgir uma leitora, não por obrigação ou para se livrar dos instrumentos que acusam as ausências de tarefas, mas por consciência, por percepção de que é preciso experimentar para saber o sabor que as coisas têm, por estímulo dos colegas, por paciência, talvez, da professora, enfim, por um conjunto de fatores estimulantes.

Chamada oral do vocabulário - de modo geral, os alunos ficam muito excitados, muitos querem ser chamados e mostram que dão importância à atividade, pois dominam significativamente o sinônimo das palavras trabalhadas.

Diante do entusiasmo para acertar tudo na chamada oral, a aluna $\mathrm{N}$ disse, um dia, em uma classe, que no dia seguinte os alunos não seriam avaliados apenas com cinco palavras, ela faria um bombardeio de palavras para cada um. Por isso, agora existe o "bombardeio de vocabulário", designação dada pelos alunos. Há novos alunos que chegam à 5 " série, curiosos em saber como é o tal bombardeio.

Atividades no Laboratório Multidisciplinar - essa etapa do trabalho auxilia na fixação do vocabulário trabalhado. No laboratório, os alunos acessam no computador variadas atividades preparadas pela equipe de tecnologia e, de maneira lúdica, realizam palavras cruzadas, caça palavras e outras brincadeiras, sempre relacionando as palavras estudadas com seus significados. 
Os alunos são estimulados a usar, nas redações, as palavras pesquisadas e, normalmente, o fazem com adequação. Esse trabalho com o livro é uma das atividades que apresenta um resultado gratificante para o aluno e para as professoras.

A partir do $2^{\circ}$ semestre, a aluna $\mathrm{N}$ acompanhou com disposição todas as atividades de leitura desenvolvidas nas aulas de Português.

\title{
Conclusão
}

É gratificante ao professor observar que os alunos se interessam pelas atividades em sala de aula. É mais gratificante ainda, quando consegue motivar alunos que se apresentam desmotivados à leitura.

O ganho é inestimável, pois a formação do hábito de leitura, a motivação para investigar, o querer conhecer são fundamentais no processo de formação de nosso alunos.

Despertar para a leitura constitui uma primeira etapa no desenvolvimento do hábito da leitura. Formar leitor crítico, e não um intérprete ingênuo, constitui tarefa posterior imprescindível ao professor, pois que leva à formação não apenas de leitores, mas de cidadãos.

Em consonância com Dumond (2002:p.10), consideramos significativo finalizar este diário, entendendo que

\begin{abstract}
A leitura não é só uma operação do intelecto humano. Pode-se dizer que tem início com o lado físico do sujeito, mas decorre, acima de tudo, da inscrição deste em determinado contexto ou espaço, do relacionamento consigo mesmo e com os outros sujeitos. Ler é trabalho de linguagem e de comunicação social.
\end{abstract}

\section{Referências Bibliográficas}

BRASIL, Ministério da Educação. Secretaria da Educação Fundamental. Parâmetros Curriculares Nacionais: Língua Portuguesa. 3.ed. Brasília: A Secretaria, 1998. 10v. em 2.

DUMONT, Lígia Maria Moreira. Os múltiplos aspectos e interfaces da leitura. Revista de Ciência da Informação - v.3 n.6 dez/02 .

LOMBARDI, Roseli Ferreira; ARBOLEA, Tânia Aparecida. Estratégias de Leitura nos Parâmetros Curriculares Nacionais. ILEEL. S.d

Abstract: In this account I present activities which were carried out in classroom and which made it possible to motivate students, so that they would get involved in the reading process.

Keywords: Portuguese, reading, teaching. 